\title{
TRTaKadeмi
}

\section{Dijital Çağda Öğrenme Aracı Olarak Oyunlaştırmanın Sağlık Okuryazarlığı Üzerindeki Rolü}

\author{
Özlem DUĞAN*
}

\begin{abstract}
Öz
Dijital teknoloji her alanda olduğu gibi sağlık alanında da büyük bir gelişim göstermektedir. Giyilebilir teknolojiler, teletıp, m-sağlık, e-sağlık, 3D yazıcılar sağlık alanında yaşanılan birkaç gelişmeden bazılarıdır. Sağlık alanında yaşanan bu gelişmeler sağlık hizmeti sunan sağlık çalışanlarına kolaylık sağlarken, hastalıkları önleme anlamında da toplumu bilinçlendirme imkânı sunmaktadır. Günümüzde özellikle her kesimden insanın dijital teknolojiyi kullandığı göz önüne alındığında tüm bu gelişmelerin sağlık okuryazarlığı alanından ayrı olması düşünülemez. Birçok toplumda sağlık okuryazarlığı seviyesinin düşüklüğü dikkate alındığında dijital sağlığın bu seviyeyi yükseltmeye yönelik önemli bir potansiyeli olduğu yapılan araştırmalarla ortaya konulmuştur. Çalışma kapsamında "oyun", "oyunlaştırma", "sağlık okuryazarlığı", "dijital araçlar" anahtar kelimeleri kullanılarak Türkçe ve İngilizce literatür taraması yapılmıştr. Elde edilen makaleler incelenmiş, sağlık alanında oyunlaştırma uygulamalarının sağlık okuryazarlığına olumlu ve olumsuz yöndeki rolü ortaya konulmuştur. Çalışma sonrasında oyunlaştırma uygulamaları ile örneğin sigarayı bırakma, obezite ile mücadele etme, düzenli egzersiz yapma, dengeli beslenme planı hazırlama, hijyen kurallarına uyma, diş firçalama gibi konularda olumlu sonuçlar alınabileceği belirlenmiştir. Her kesimden insanın dijital araçlara uyumunun zorluğu, dijital bağımlılığı artıracağı endişesi, internet ve teknoloji altyapı yetersizliği gibi konular da olumsuz olarak görülen sorunların başında gelmektedir. Bu bağlamda sağlık alanında oyunlaştırma, bireylerin sağlık davranışlarında olumlu yönde bir kalıcı değişikliği desteklemek ve sürdürmek adına önemli bir araç olarak kabul edilebilir. Literatür taraması ve yapılan araştırmaların sonuçları bağlamında sağlık alanında oyunlaştırmanın olumsuz yönleri olsa da sağlık okuryazarlığının temelini oluşturan anlayabilme ve kavrayabilme yeterliliğini geliştireceği ifade edilebilir.
\end{abstract}

Anahtar Kelimeler: Sağlık, Sağlık Okuryazarlığı, Oyun, Oyunlaştırma, Dijital Araçlar

*Doç. Dr., Uşak Üniversitesi İletişim Fakültesi Halkla İlişkiler ve Reklamcılık Bölümü, ozlem.dugan@usak.edu.tr

\section{Derleme Makale}

Geliş Tarihi: 01.07.2021

Revizyon Tarihi: 16.11.2021

Kabul Tarihi: 14.01.2022 


\title{
TRTakadeмi
}

ISSN 2149-9446 | Volume 07 | Issue 14 | January 2022 | Social Media

\section{The Role of Gamification as a Learning Tool on Health Literacy in the Digital Age}

\author{
Özlem DUĞAN
}

\begin{abstract}
Wearable technologies, telemedicine, $\mathrm{m}$-health, e-health, 3D printers are just a few of the developments in the field of health. While these developments in the field of health provide convenience to health workers who provide health services, they also provide the opportunity to raise awareness of the society in terms of preventing diseases. Considering that people from all walks of life use digital technology today, it is unthinkable for all these developments to be separate from the field of health literacy. Considering the low level of health literacy in many societies, studies have shown that digital health has a significant potential to increase this level. Within the scope of the study, Turkish and English literature review was conducted using the keywords "game", "gamification", "health literacy", "digital tools". The obtained articles were examined, and the positive and negative roles of gamification practices in the field of health on health literacy were revealed. After the study, it was determined that positive results could be obtained with gamification practices, such as quitting smoking, fighting obesity, exercising regularly, preparing a balanced diet plan, complying with hygiene rules, and brushing teeth. Issues such as the difficulty of adapting people from all walks of life to digital tools, the concern that it will increase digital addiction, and the lack of internet and technology infrastructure are among the problems that are seen as negative. In this context, gamification in the field of health can be considered as an important tool to support and maintain a positive permanent change in the health behaviors of individuals. In the context of the literature review and the results of the researches, it can be stated that gamification in the field of health will improve the ability to understand and comprehend, which is the basis of health literacy, although there are negative aspects.
\end{abstract}

Keywords: Health, Health Literacy, Game, Gamification, Digital Tools 


\section{Giriş}

Geçmişten günümüze oyunlar, bir toplumun kültürünü anlatan en önemli göstergelerinden biri olarak değerlendirilirken günümüzde aynı zamanda eğitim, güvenlik, politika, askerî, reklam, tanıtım ve sağlık alanında öğrenme amaçlı kullanılan bir yöntem hâline gelmiştir. İletişim teknolojilerinde yaşanan gelişmelerle birlikte artık geleneksel öğrenme yöntemleri, yeni nesil için sıkıcı bir öğrenme yöntemi olarak görülebilmektedir. Özellikle yeni nesil tarafindan tercih edilen ve yine bu kişilerin zamanlarının çoğunluğunu sanal ortamda geçirdikleri göz önünde bulundurulduğunda, oyunlaştırma özellikle eğitimin yanı sıra sağlık alanında da etkili olacak gibi görünmektedir. Hiç kuşkusuz her birey sağlıklı olmak ve sağlık okuryazarlığı düzeyini üst sıralara taşımak istemektedir. Sağlık okuryazarlığı düzeyinin artması sağlıklı bir neslin oluşmasına katkı sağlamaktadır. Sağlık alanında bilinç düzeyinin artması, ülkeleri ekonomik anlamda olumlu yönde etkilemektedir. Bu nedenle her ülke, imkânları ölçüsünde sağlık alanına yatırım yapmakta ve yenilikleri yakından takip etmeye çalışmaktadır. Kamu kurum ve kuruluşları ile özel sektörün yanı sıra sivil toplum kuruluşları da sağlıklı bir neslin oluşmasına katkı sağlamakta ve sağlık okuryazarlığını artırmaya yönelik çabalara girmektedir. Örneğin kâr amacı gütmeyen, çocukların ve gençlerin yaşam kalitesini artırmaya yönelik çalışmaları ile tanınan HopeLab Vakfi tarafindan "Re-Mission (İyileşme)" isimli oyun, hastalara moral vermek ve hastalıkları kontrol altına alıp tedavi yöntemlerini öğretmek amacıyla hazırlanmıştır. Bir ilaç şirketi tarafindan hazırlanan ağrı semptomlarını işaretleyerek kullanıcıları oyuna dâhil ettiği ve omur iltihaplanması ile ilgili halkı bilgilendirmeye yönelik "Back in Play" isimli oyunun farkındalığı artırdığı belirtilmektedir. Yine bir ilaç şirketi tarafindan hazırlanan "Healthseeker" isimli Facebook bağlantılı oyun diyabet hakkında bilgilendirme yapmaktadır. Bu bağlamda hedef ve ödül esaslarına dayandığı için bireyi motive eden oyunlaştırma uygulamalarının sağlık alanında eğitici rolü belirginleşmektedir. Ernst ve Young Araştırma ve Danışmanlık Şirketinin oyunlaştırma ile ilgili hazırladığı raporda, oyunlaştırma uygulamaları, sağlık kampanyaları için önemli bir potansiyel alan olarak görülmektedir. Oyunlaştırma, aynı zamanda harita kullanımı ile en yakın hastaneyi belirleme, maraton egzersiz ve dengeli beslenme programı oluşturma, herhangi bir hastalık ile ilgili bilinçlenme seviyesini artırma gibi konularda sağlık okuryazarlığını artırıcı, destekleyici bir rol oynamaktadır (Sağlık Sektörü ve Oyunlaştırma Trendleri, 2012). Sağlık alanında oyunlaştırmanın, bazı araştırmacılar tarafindan dijital bağımlılığı artırıcı bir rol oynayacağı ifade edilse de oyun ve oyun uygulamalarının bireylerin sağıık alanında bilgilerini artırdığı, hastalıklara karşı bireylerin tutum, algı ve davranışlarının olumlu yönde 
etkilendiği kabul edilmektedir. Bu bağlamda çalışmada sağlık okuryazarlığı, dijital alanda sağlık ve oyunlaştırma uygulamaları çerçevesinde oyunlaştırmanın sağlık okuryazarlığı üzerindeki rolü ortaya konulmaya çalışılmıştır. Çalışma çerçevesinde araştırma soruları şu şekilde oluşturulmuştur:

- Sağlığa yönelik oyunlaştırma uygulamalarının olumlu yönleri nelerdir?

- Sağlığa yönelik oyunlaştırma uygulamalarının olumsuz yönleri nelerdir?

- Oyunlaştırma uygulamalarının sağlık okuryazarlığı üzerindeki rolü nelerdir?

Bu çalışmada literatür incelemesi yapılmıştır. Hart (2001), literatür incelemesini sınırlı bir akademik alanda araştırmalara dayalı çalışmaların değerlendirilmesi ve bilgi tabanının geliştirilmesi amacıyla alt parçalarına ayrılarak yeniden organize edilmesi, sentezlenmesi ve yorumlanması olarak tanımlamaktadır. Çalışma kapsamında "oyun", "oyunlaştırma", "sağlık okuryazarlığı", "dijital araçlar" anahtar kelimeleri kullanılarak Türkçe ve İngilizce literatür taraması yapılmıştır. Elde edilen veriler incelenerek sağlık alanında oyunlaştırma uygulamalarının sağlık okuryazarlığı üzerindeki rolü, sağlığa yönelik oyunlaştırma uygulamalarının olumlu ve olumsuz yönleri ortaya konulmaya çalışılmıştır.

\section{Oyun ve Oyunlaştırma}

Prensky'e (2007) göre oyun; kural, hedef, geri bildirim, rekabet, meydan okuma, etkileşim gibi unsurları içermektedir. Jarvinen'e (2008) göre oyun; belli bir ortamı, kuralı, bağlamı olan oyuncunun dâhil olduğu bir sistemdir. Juul (2003), oyunu ölçülebilir bir sonucu olan ve bu sonucu etkilemek için oyuncunun dâhil edildiği bir sistem olarak tanımlamaktadır. Oyunlar, zamanla değişim ve gelişim göstermiş ve günümüzde dijital ortama taşınmış durumdadır. Çağımızda iletişim teknolojisinin gelişmesiyle birlikte artk oyunları sadece çocuklar değil, her yaştan insan oynayabilmektedir. Dijital ortamda oyuna ilginin artması bu alana yatırım oranlarını önemli oranda artırmıştır. Aynı zamanda bu alana yatırım yapanların yaş, cinsiyet ve kültürel özelliklere dikkat ederek her kesime hitap edebilecek tarzda oyunlar tasarladıkları görülmektedir. Bu çerçevede oyunlaştırma, oyun unsurlarının oyun olmayan içeriklerde kullanıcıların deneyimini ve ilgisini arttırmak amacıyla kullanılması olarak ifade edilebilir (Domínguez vd., 2013, s. 380). Kullanıcıların ihtiyaç ve hedeflerini dikkate alan bir yaklaşım olarak ifade edilen oyunlaştırma (Kapp, 2012), oyundaki kuralların ve düşünce biçiminin kullanıcıların ilgisini çekmek ve problemlerini çözmek için kullanılmasıdır (Zichermann ve Cunnigham, 2011). Oyunlaştırmanın; müze gezileri, hayvanat bahçeleri gibi öğrenme alanlarında uygulanmasını öneren Chen ve arkadaşlarının (2016) yanı 
sıra Buckley ve Doyle (2016)'nun, oyunlaştırmanın öğreneni ödüllendiren bir sistem olması nedeniyle bu sürecin motivasyonu olumsuz yönde etkilediği şeklinde görüşler bulunsa da öğrencilerin gruplar şeklinde çalışmaları hâlinde performanslarının sürekliliği açısından olumlu katkı sağladığı belirlenmiştir (Pesare vd., 2016, s. 19; Juárez ve Carballo, 2016). Temel mikrobiyoloji eğitiminde oyunlaşttrma yönteminin hedeflere ulaşmada, öğrenmenin kalıcılığında ve öğrenme algılarında etkilerini araştırmak üzere yapılan çalışmada, eğitim yönteminin kontrol grubu tarafindan öğrenmeye ve öğrenme sürecine etkilerine yönelik ifadelerin daha yüksek puanlandığı görülmüştür (Karahan vd. 2014, s. 184). Eğitim, ekonomi, pazarlama, güvenlik, politika, reklam ve üretim sektörünün yanı sıra oyunlaştırma; günümüzde sağlık alanında da kullanılmaktadır. Piyasaya sürülmesinden bu yana oyunlaştırma kavramı hızla gelişmiş ve iş yeri, eğitim, pazarlama ve sağlık gibi çeşitli alanlarda uygulayıcılar ve araştırmacılar tarafindan yaygın bir şekilde benimsenmiştir (Hamari ve Koivisto, 2015). Mobil sağlık uygulamalarından biri olarak bilinen oyunlaştırmanın sağlık davranışları, hastalıklara yönelik tutumlar ve algılar üzerinde etkilerine yönelik birçok çalışma yapılmaktadır. Interaktif oyunlaştırmalar yoluyla hastaların ihtiyaçlarını belirlemek, davranışlarını anlamak ve birtakım istatistiksel bilgi toplayabilmek mümkündür. (Tezcan, 2016, s. 57-58). Oyunlaştırmanın ilgi çeken iki nedeni bulunmaktadır. Birinci neden, tüketicilerin isteklerine dayanmaktadır. Yeni bilgi ve iletişim teknolojileri özellikle akıllı telefonların oyun tasarımcılarına hedeflenecek daha büyük bir kitle sağlaması ve kullanımı daha çekici hâle getiren interaktif sağıı araçları dizaynında yardımcı olması oyunlaştırmanın sağlık alanında kullanımını artırmaktadır. İkinci neden ise geliştiricilerin en yeni davranışsal sezgilerini elektronik araçlar içerisine katmadaki heves ve gönüllülüğüdür (King vd. 2013). "Fun is The Future: A Collection of Compelling Gamification Success Stories" isimli kitabın yazarları Joy ve Chiramel (2017, s. 4), oyunlaştırmanın çalışanların performanslarını ölçmede yardımcı olduğunu, bilgiyi geliştirdiğini, başarıyı arttırdığını, etkileşimi yükselttiğini, öğrenme ve gelişmeyi güçlendirdiğini vurgulamaktadırlar.

\section{Sağlık ve Oyunlaştırma}

Dijital teknolojinin bireylerin hayatına aktif bir şekilde girmesi ile birlikte bu araçlar bireyin sağlığını korumak, sağlık alanında daha fazla bilgi sahibi olmak gibi konularda kullanılmasının yanı sıra harita kullanımı ile en yakın hastaneyi belirleme, egzersiz ve dengeli beslenme programı oluşturma, herhangi bir hastalık ile ilgili bilinçlenme seviyesini artırma gibi konularda da sağlık okuryazarlığını destekleyici bir araç olarak kullanılabilmektedir. British Medical Journal (BMJ) Klinik Direktörü Kieran Wash, sağı̆̆ın oyunlaştırılmasını eleştirel bir bakış açısıyla değer- 
lendirmesine rağmen uygulamaların hastalıklarla mücadelede önemli olacağını vurgulamaktadır. Aynı çerçevede Boehringer Ingelheim Dijital İletişim Direktörü John Pugh, oyunlaştırmada önemli olanın hastalıklar ile ilgili farkındalık oluşturmak, hastaları ilaçlara yönelik bilgilendirmek ve ilaç sektörünün tanınırlığını artırmak olduğunu ifade etmektedir (Sağlık Sektörü ve Oyunlaştırma Trendleri, 2012). Sağlıktan yarar sağladığını kanıtlamış olan oyunların bir başka kullanımı, teşhis edilmiş veya belirli bir tıbbi duruma maruz kalmış insanlar üzerinde öz yönetim becerilerini eğitmek veya geliştirmektir (Bamidis vd., 2016, s. 112-113). Sağlık alanında en iyi oyunlaştırma uygulamalarına; sağlık ve spor alanında Nike Plus, sosyal alanda Foursquare oyunlaştirma uygulaması örnek verilmektedir. Foursquare uygulaması, kullanıcıların bulundukları yerleri puanlamalarına, yorumlamalarına, uygun mekân önerileri sunabilmelerine imkân sağlayan bir sisteme sahiptir. Uygulama çerçevesinde bulunulan yer bildirilerek rozet kazanılır, puan toplanır ve liderlik tablosuna yerleşilir. Bu uygulama yer bildirmek ve yorum yapmak için motivasyon oluşturmaktadır. Nike Plus, kişilerin spor yapmak için isteklerini artırmayı amaçlayan bir uygulamadır. Kullanıcılara verilen bileklik aracılığıyla koştukları süre ve mesafe belirlenir. Kullanıcı skoru aşmaya çalışırken aynı anda diğer kullanıcılarla yarışır. Kullanıcı skora göre lider tablosuna yerleşir (Zichermann ve Cunningham, 2011). Nike şirketi, bu uygulama ile marka bilinirliliğini artırmanın yanı sıra söz konusu uygulamayı oyuna katılımı artırarak önemli bir tanıtım aracı olarak kullanmıştır. Nike Plus uygulaması, kullanıcıların spor alışkanlığı kazanmasında ve bu alışkanlığın sürekliliğinde memnuniyet oluşturmuştur. Sağlık ve fitness uygulamalarının yanı sıra App Store ve Google Play üzerinde uygulamalar yapılabilmektedir. Pediatri alanında bir ilaç şirketi tarafindan geliştirilen Abbott uygulaması, çocukluk dönemi obezitesi için geliştirilen Change Talk uygulaması, çocuk ve yetişkinlerde dikkat eksikliği için geliştirilen CogCubed-Cognitive Games For Health uygulaması, diyabet hastaları için geliştirilen Patient Partner uygulaması ve ilaç kullanan hastalar için hatırlatma yapan ManhoHealth uygulaması ve son olarak fitness için Fitocracy uygulaması bulunmaktadır (Zülam, 2019, s. 2122). Egzersiz için tercih edilen Fitocracy los ve Android işletim sistemine uygun olarak tasarlanan dijital oyun sağlık uygulaması olarak dikkat çekmektedir. Bu uygulama ile kullanıcılar oyunlaştırma bileşenleri ile birlikte sosyal ve rekabet ortamında, hareketin fotoğrafları, kaç set ve nasıl yapılacağı ile ilgili bilgilerle düzenli bir şekilde egzersiz yapmaktadır. Egzersiz sonucunda puanlara göre uygulamada başarılı olanlar rozetler ile ödüllendirilmektedir (Zülam, 2019, s. 46-48). Kâr amacı gütmeyen, sağıı̆ın geliştirilmesi ve kronik hastaların yaşam kalitesini yükseltme amacını taşıyan HopeLab Vakfi tarafindan Re-Mission (İileşme) isimli oyunda hastalara moral vermek ve hastalıklarını kontrol altına almak amaçlanmaktadır. 
Yapılan araştırma sonucunda, bu oyunu oynayan çocukların kanser tedavisine karşı davranışlarının geliştiği belirlenmiştir. Bir şirket tarafindan geliştirilen "Paper to Patient" isimli oyun, kronik obstrüktif akciğer hastalığına sahip hastaların tedavisinde doktorlara yardımcı olmaktadır. Yine bir ilaç şirketinin "Back in Play" isimli oyunu kullanıcıları ağrı semptomlarını işaretleyerek oyuna dâhil etmesi ve omur iltihaplanması ile ilgili halkı bilgilendirmeye yönelik farkındalık yaratmasıyla hekimlere destek olmaktadır. Healthseeker isimli Facebook'a entegre oyun ile diyabet hakkında bilgilendirici faaliyetler yapılmaktadır (Sağlık Sektörü ve Oyunlaştırma Trendleri, 2012). Physiotherapist oyunu ile günlük yapılabilecek egzersizler, güne başlama egzersizleri ve ofis ortamında yapılabilecek egzersizler görsel olarak kullanıcılara sunulmaktadır (Tüfekçi, 2016, s. 32). Günümüzde bu oyunların arasına her geçen gün yenileri eklenmektedir.

\subsection{Oyunlaştırmanın Sağlığa Olumlu Etkisine Yönelik Araştırmalar}

Oyunlaştırmanın sağlık alanına olumlu yönde katkısına yönelik bugüne kadar birçok çalışma yapılmıştır. Kostenius ve arkadaşları (2018, s. 354) tarafindan okul çocuklarında (10-12 yaş arası) iki ay boyunca 18 çocukla oyunlaştırmanın fiziksel aktiviteyi ve öğrenmeyi teşvik etmek için nasıl kullanılacağı üzerine bir atölye çalışması yapılmıştır. Çalışma kapsamında okulda dijital oyunlar kullanılarak fiziksel aktivite ve sağlık eğitimi firsatları değerlendirilmiştir. Çalışma doğrultusunda dijital oyunun sağlık eğitiminde faydalı olduğu ve sağlık bilincine sahip olma yetkinliklerini geliştirdiği belirlenmiştir. Pittsburgh Üniversitesi Eczacılık Okulundaki sağlık hizmetlerine yönelik öğrenciler ve öğretim üyeleri ile yapılan çalışmada, oyunlaştırmanın bilgiyi artırdığı belirlenmiştir (Wolf vd., 2018, s. 305). Sağlık profesyonellerinin yardımı ile insanların kilo vermesine yönelik bir oyunlaştırma tabanlı etkileşimli teknolojinin kullanılmasının kullanıcıların motivasyonunu artırabileceği tespit edilmiştir (Wen, 2017, s. 533). Nijerya'da ve Sahra Altı Afrika'da yaşayan ergenlerin tuz, şeker ve doymuş yağ bakımından zengin gıdaları tüketmelerine yönelik yapılan çalışmada, oyunlaştırmanın beslenme alışkanlığını etkileyip etkilemediği belirlenmeye çalışılmıştır. Nijerya'da 3 ortaokulda 3-4 hafta boyunca masa oyunları, kulüpler ve kuponlar yardımıyla beslenmenin oyunlaştırılması tanıtılmıştır. Üç ortaokulda 11'inci ve 12'nci sınıf öğrencileriyle yarı yapılandırılmış odak grupları ile çalışılmıştır. Bu süreçte katılımcılara yeme alışkanlıkları, beslenme hakkındaki tutumları ve bunların bilgilerini nasıl etkilediği sorulmuştur. Katılımcılar, müdahalenin algılarını ve tercihlerini değiştirdiğini, daha besleyici gıdaları diyetlerine dâhil ederek ve daha fazla fiziksel aktiviteye girerek davranışlarını değiştirmelerine yol açtığını bildirmiştir. İyileştirilmiş yeme davranışı, artan fiziksel aktivite, iyileştirilmiş genel refah, artan beslenme bilgisi 
ve başkalarını etkilemek olumlu sonuçlar olarak belirlenmiştir. Bu sonuçlar, beslenmenin oyunlaştırılmasının, kısa vadede ergenler arasında diyet davranışında iyileşmelere yol açabileceğini göstermiştir. Odak grup tartş̧malarından çıkan beş tema; beslenmenin oyunlaştırılmasının ergenlerin beslenme ve sağlıklı beslenme ile ilgili bilgi, tutum ve davranışlarını olumlu yönde etkileyebileceğini ortaya koymuştur (Ezezika vd., 2018, s. 143). Radovick ve arkadaşları (2018, s. 76-77) tarafindan yapılan çalışmada etkileşimli mobil sağlık (akıllı telefon, tablet vb.) kullanımının diyabet gibi kronik rahatsızlıkları olan çocuklarda olumlu davranışı teşvik etmede başarı gösterdiği gözlemlenmiştir. Çocuğun anladığı ve kabul ettiği bir formatta eğitim vererek bağlılığın neden önemli olduğunu açıklamak, enjeksiyonun uygulanmasıyla ilişkili kaygı ve stresi azaltmak için bir mekanizma sağlamak, devam eden katılımı teşvik etmek için geri bildirim sağlamak gibi çocuklarda sağlıkla ilgili davranışı olumlu yönde desteklediği ortaya konulmuştur. Oyun tabanlı öğrenmenin ve oyunlaştırmanın ergen öğrencilerin cinsel sağlık eğitimini ne ölçüde geliştirebileceğini ortaya koymak amacıyla yapılan çalışmada Haruna ve arkadaşları (2018, s. 18-19) öğrencileri 5 hafta boyunca takip etmiş, 120 öğrencinin sonuçlarını değerlendirmiş ve iki yenilikçi öğretim yaklaşımının ergen öğrencilerin cinsel sağlık eğitimini geliştirmek için kullanılabileceğini ortaya koymuşlardır. Rajani ve arkadaşları (2019, s. 6-7) tarafindan yapılan başka bir çalışmada, psikolojik ve davranışsal sonuçları olumlu yönde etkileyebilecek olan oyunlaştırmanın sigarayı bırakmada etkili olduğu belirlenmiştir. Sigarayı bırakma için mobil uygulamaların ikna edici tasarımın önemli bir parçası olabileceğini göstermiştir. Çalışmada sigarayı bırakmak için oyunlaştırılmış mobil uygulamaların geliştirilmesinin, oyun uzmanları, yazılım geliştiricileri, davranış değişikliği uzmanları ve sigarayı bırakma uzmanları arasında iş birliği de önerilmektedir.

\subsection{Oyunlaştırmanın Sağlığa Olumsuz Etkisine Yönelik Araştırmalar}

Sağıı alanına yönelik oyunlaştırmanın faydasının yanı sıra bazı konularda zorluklar ve kuşkulara da neden olduğu yapılan araştırmalarla belirlenmiştir. Sağlık sistemi içerisinde hastalar, sağlık çalışanları, paydaşlar ve sistemi düzenleyenler için faydaları olan dijital sağlık teknolojilerinden ve uygulamalarından yararlanmayı engelleyen bazı durumlar söz konusudur. Bunlardan birincisi, bireylere ait bilgiler internet aracılığıyla depolanmaktadır. Bu bilgiler bireyler hakkında önemli sağlık ve kişisel bilgileri içermektedir. Bir veri hırsızlığı ya da teknik problemler bu bilgilere erişime neden olabilir (Blumenthal, 2017, s. 15). İkinci engel olabilecek durum, bireylerin sağlık okuryazarlık durumu ve bilgisayar teknolojileri kullanım düzeyidir. Bu durum, yeterli oranda faydalanmayı engelleyebilir (Mackert vd., 2016, s. 13-14). 
Diğer bir engel ise bireylerin ve sağlık çalışanlarının internet ve teknoloji altyapı yetersizliğidir (Ajami ve Bagheri-Tadi, 2013, s. 132-133). Sağlık alanında oyunlaştırmanın istenmeyen yan etkilerini araştıran bir çalışmada, beş istenmeyen yan etki grubu oluşturulmuştur. Birincisi, olumsuz motivasyonel sonuçlar oyunlaşttrmanın ana amacına ulaşılamayan yan etkileri tanımlar. Bu grubun yan etkilerinin ortaya çıkma nedenleri çeşitlidir. Geliştiriciler, oyun tasarımı bilgisini tasarım sürecine dâhil etmemeye karar verdiğinde ve bunun yerine uygulanması kolay ve kısa vadeli davranış değişikliği vaat eden dışsal ödüllere dayanan "ucuz" oyunlaştırma çözümlerini tercih ettiklerinde, oyunlaştırma yaklaşımları büyük olasılıkla başarısız olacaktır. İkinci olarak, sağlık bağlamının benzersiz ciddiyetinin yetersiz değerlendirilmesi ve uygunsuz oyunlaşttrma ögelerinin seçilmesinden kaynaklanır. Üçüncüsü, egzersiz bütünlüğünün azalması, kullanıcı için doğrudan sağlıkla ilgili dezavantajlara yol açabilecek istenmeyen yan etkileri açıklar. Bu nedenle, bu yan etkilerin ortaya çıkmasını önlemek önemlidir. Dördüncüsü, kullanıcıların demoralizasyonu, kullanıcıların haksız muamele gördükleri için sistemi kullanmayı bırakmalarına neden olabilecek istenmeyen yan etkileri açıklar. Beşinci olarak, sınırların aşılması, oyun geliştiricileri için yasal sorunlara yol açabilecek yan etkileri açıklamaktadır (Schmidt, Kraepelin vd. 2019). Oyunlaştırma ayrıca kronik hastalıklara yönelik olarak uygulandığında riskli bir alternatif olabilir. Hastalar, kronik veya dejeneratif hastalıklardan muzdarip olduğunda oyunlaştırma uygulamalarını kullanma konusunda ciddi bir risk oluşabilir çünkü artan engelliliklerinin farkındalığını arttırır ve bu nedenle onların motivasyonunu düşürebilir (Gallan vd., 2013, s. 338). Leclercq ve arkadaşları çalışmalarında (2018, s. 93-94), bir oyunlaştırma deneyiminde kaybetme durumunun bireyleri nasıl etkilediğini incelemiş, kaybetme-kazanma durumunun oyunlaştırmanın yararlarını zayıflattğı ve rekabetin kaybedilmesi durumunda müşteri deneyimi ve katılımını olumsuz yönde etkilediğini ortaya koymuştur. Bir başka araştırmada ise oyunlaştırmanın topluluklarda yorum yapma gibi fazla zahmet gerektirmeyen eylemlerin yapılma oranını niceliksel olarak artırsa da belirli bir görev için harcanan çabanın kapsamını ve niteliğini artırmada büyük ölçüde etkisiz kaldığı vurgulanmaktadır (Zimmerling vd., 2019).

\section{Sağlık Okuryazarlığı ve Oyunlaştırma}

Alanyazında yapılan araştırmalar doğrultusunda sağlık alanında oyunlaştırmanın bazı olumsuz yönleri bulunsa da genel olarak sağlık alanına olumlu yönde katkı sağladığı ortaya çıkmaktadır. Oyunlaştırma; hastanenin rotasını belirleme, çeşitli sağıı uygulamaları aracılığıyla egzersiz oluşturma, ilaç kullanımı saatini ayarlama, kalp masajı yapabilme, dengeli beslenme gibi bilinçli ve sağlıklı olma yolunda 
kullanılan, kolaylaştırıcı bir araç olarak ifade edilebilmektedir. Bu bağlamda oyunlaştırmanın sağıı okuryazarlığını keyifli hâle getirici ve hatırlatıcı bir araç olduğu değerlendirilebilir. Genç neslin dijital teknolojiyi başarılı bir şekilde kullandığı göz önüne alındığında oyunlaştırmanın sağlık alanında etkisinin ileriki yıllarda daha da artacağı söylenebilir. Dijital teknolojinin hızlı ve çabuk erişilebilir olması, küçüklüğü sayesinde cepte taşınabilmesi sağlık okuryazarlığını geliştirmesi yönünde önemli bir potansiyel olduğu ifade edilebilir. Bu doğrultuda günlük hayatta sağlık ile ilgili kararlar almak, yaşam kalitesini yükseltmek, hastalıkları önlemek için gerekli bilgileri anlama yeterliliği olarak tanımlanan sağlık okuryazarlığı (Sorensen vd., 2012, s. 80), reçetelerdeki bilgileri, randevu fişleri, sağlık alanında eğitim amaçlı hazırlanan broşürleri, doktorların açıklamalarını anlayabilme becerisini içermektedir (Nutbeam, 2000). Sağlık okuryazarlığı sürecinde; hastaların, hastalıkları ve tedavisi ile ilgili bilgiyi değerlendirme, riskleri ve faydaları analiz etme, test sonuçlarını anlamlandırma becerisine sahip olması beklenir (Rudd, vd., 2004). Sağlık eğitiminin birinci hedefi, çocukluk döneminden başlayarak her yaş grubunda sağlık bilincini yükseltmek ve sağlık okuryazarlık düzeyini artırmaktır (Yılmazel ve Çetinkaya, 2016, s. 73). Sağlık okuryazarlığının, bireyin sağlığını koruyucu bir rol oynamasının yanı sıra sağlıkta maliyeti azaltan önemli bir rolü de bulunmaktadır. Bu nedenle sağlık okuryazarlığının düşük düzeyde olması, koruyucu sağlık hizmetlerinin düşük seviyede kullanımına, sağlık bakımı arayışında gecikmeye, bireyin tıbbi durumunu değerlendirmesinde yetersizliğe, tıbbi önerilere bağlılıkta yetersizliğe, sağlık bakım maliyetlerinin yükselmesine ve mortalitede artışa neden olmaktadır (Freedman vd., 2009). Eichler ve arkadaşları (2009, s. 321) sağlık okuryazarlığı düzeyinin düşüklüğünün sağlık bakımına maliyetini araştırdıkları çalışmalarında 1980-2008 yılları arasında Amerika, Kanada, Norveç, Meksika, İtalya ve Bermuda'da 2340 yayını incelemişler ve 10 yayını çalışmaya dâhil etmişlerdir. Çalışma sonucunda sağlık okuryazarlığı düzeyinin düşük olmasının toplam sağlık bakımına yılık \%3-5 oranında ek maliyete ve sınırlı sağlık okuryazarlığı olan kişi başına yılık ek harcamaların 143 ila 7798 dolar arasında değişen maliyetlere neden olduğunu belirlemişlerdir. Cimasi ve arkadaşları (2013, s. 1), önlenebilir yatışlarla sağlık okuryazarlığı arasında istatistiksel açıdan anlamlı pozitif bir ilişki bulmuşlardır. ABD'de 10 eyaletten 65 yaş üstü 7334 kişi ile yapılan bir araştırmada, yetersiz sağlık okuryazarlığının hasta memnuniyetini azalttı̆̆ı, koruyucu hizmete uyumu azalttı̆ı bu nedenle de daha fazla sağlık hizmeti alındığı bunun da sağlık harcamasını arttırdığı ifade edilmiştir (MacLeod vd., 2017). Sağlık okuryazarlık düzeyinin azlığının iletişim sorunlarına neden olduğu belirtilmektedir (Parker vd., 1999). Sağlık okuryazarlığı seviyesinin düşük olması, sağlık bilgilerini anlama açısından sorunlara neden olmakta ve dolayısıyla hastanın 
hastanede yatı̧ süresini uzatmaktadır (Osborne, 2013). Yeterli sağlık okuryazarlığı hastalık riskini azaltırken aynı zamanda sağlıklı olmanın bir gereği olarak ortaya çıkmaktadır. Yeterli sağlık okuryazarlığında egzersiz yapma oranı \%36,6, sağlık okuryazarlığı yetersizliğinde egzersiz yapma oranı \%29 olarak tespit edilmiştir. Yeterli sağlık okuryazarlığı meyve sebze tüketme oranını \%47,4 etkilerken, yetersiz sağlık okuryazarlığında bu oran \%29,3 seviyelerinde kalmaktadır (Wagner vd., 2007). Sekiz Avrupa ülkesinde 15 yaş ve üzerinde olan 8 bin kişi ile yapılan çalışmada Hollanda'da \%23,7 ve Bulgaristan'da \%53,7 oranında katılımcının sağlık okuryazarlığı düşük çıkmıştır. Polonya \%42,2 ile yeterli ve çok iyi puan alırken İspanya \%36,9 ile en düşük seviyede bulunmuştur (Kanj ve Mitic, 2009). Sağlık okuryazarlığı seviyelerini ve etkileyen faktörleri araşttrmak için yapılan çalışmada, bir üniversitenin aile hekimliği polikliniğine başvuran gönüllü hastaların \%50,6'sı yetersiz, \%25,1'i sorunlu sağlık okuryazarlığı düzeyi ortaya çıkmıştır (Yakar vd., 2019, s. 27). Yapılan bir çalışmada, hastaların sağlık okuryazarlığının düşük olmasının en önemli nedenleri belirlenmiştir. Buna göre sağlık bilgilerinin karmaşık olması, eğitim düzeyinin düşük olması, yaşlı insanların okuma yeteneklerinin zayıf olması, davranış değişikliğini hedefleyen yönlendirmelerin yetersiz kalması önemli nedenler arasındadır (Ölmez ve Barkan, 2015, s. 126). Sağlık okuryazarlık oranını yükseltmede sağlık çalışanlarının önemli rolü bulunmaktadır. Hasta ile daha iyi iletişim kurmak için hastayı dinlemek, hastayı anlayabileceği dilde bilgilendirmek, hastaların rahat olmasını sağlamak, yazıIı materyal ve mesajların hazırlanmasında hasta ile iş birliği yapmak, iletişimin hastayı nasıl etkilediğini değerlendirmek gerekmektedir (Şahinöz vd., 2018, s. 73). Söz konusu çalışmalar çerçevesinde sağlık okuryazarlığı düzeyini yükseltmek için oyunlaştırmanın kullanılması önemli bir seçenek olarak değerlendirilebilir. Sağlıklı yaşamak için gereken kuralları ve bilgileri bireye öğreten, hatırlatan ve uygulatan dijital oyunların artmasının sağlık okuryazarlığını olumlu yönde etkileyeceğini ifade etmek mümkündür. Sağlık ile ilgili faaliyetlerin, kampanyaların ve mesajların hedef kitleye ulaştırılmasında geleneksel medya araçları eskiden çok kullanılırken günümüzde dijital araçlar daha çok tercih edilmektedir. Dijital araçların kullanımı aynı zamanda hedef kitle ile interaktif bir iletişime girilmesine imkân sağlamaktadır (Bottorff vd., 2014). Sağıı okuryazarlığının artmasında iletişim teknolojilerinin önemli katkısı bulunmaktadır. Özellikle sağlık çalışanları için büyük kolaylıklar sağlayan iletişim teknolojilerinin (Şahinöz vd., 2018, s. 73) sağlık hizmetinde kullanımı sağıı hizmet sunucularına önemli bilgiler üretmektedir. Bu bağlamda dijital sağlık; bireyin sağlığını kontrol eden, tedavi protokollerine uyumunu gösteren, koruyucu sağlığı teşvik eden, birey ve sağlık çalışanının iletişimini sağlayan sistemler ve araçlar bütünü olarak tanımlanmaktadır (Lupton, 2013, s. 
257). Dijital sağlık; hastalar, sağlık çalışanları, sağlık alanına yatırım yapanlar ve benzerleri arasındaki sınırları yeniden tanımlayarak sağlık alanında bir değişim ortaya koymaktadır (Herselman vd., 2016, s. 2). Bu teknolojiler insan sağlığının geliştirilmesini amaçlamaktadır (Hudes, 2017, s. 1). Sağlık alanında dijital uygulamaların arttğını söylemek mümkündür. Bu uygulamalardan bazıları; giyilebilir teknolojiler, sanal gerçeklik teknolojileri, teletıp, mobil sağlık teknolojileri, e-sağlık, 3D yazıcılar ve kovid-19 pandemisi ile uygulanmaya başlanılan hayat eve sığar uygulamasıdır.

\subsection{Giyilebilir Teknolojiler}

Giyilebilir teknolojiler; elbise veya aksesuarların içine yerleştirilebilen ya da vücuda yapıştırılabilen elektronik cihazlardır. Bu cihazlar, akıllı cep telefonlarının ve bilgisayarların yapamadığı birçok işlemi yapabilmektedir (Tehrani ve Michael, 2014). Giyilebilir cihazlar arasında bileklikler, saatler, gözlükler, akıllı kumaşlar, lensler, yüzükler, kafa bantları, e-tekstil ürünleri ve işitme cihazları sayılabilir. Bu cihazlar aracılığıyla kalp, diyabet, hipertansiyon ve obezite gibi hastalıklar erken dönemlerde teşhis edilmekte ve belirlenen bu hastalıklara yönelik tedaviler geliştirilmektedir (Bonato, 2010, s. 2023). Yapılan bir çalışmada, yaşlı yetişkinlerin ev ortamında (20 yaşlı yetişkin) 4 hafta boyunca akılı telefon uygulamasını ve etkinlik izleme cihazını (fMOOC) kullanmaları sağlanmış ve bu doğrultuda kuvvet, fiziksel aktivite, dengeleme yeteneği ve dayanıklılıktaki değişiklikleri ölçerek eğitimin etkinliği incelenmiştir. Sonuçlar katılımcıların \%60'ının düzenli olarak eğitim programına katıldığını göstermektedir. Sonuç olarak giyilebilir bir fitness eğitim programı, yaşlı yetişkinleri fiziksel olarak daha aktif olmaya motive edebilmektedir (Steinert vd., 2018). Oyunlaştırmanın sağlıklı bir yaşam tarzı için giyilebilir cihazların benimsenmesine yardımcı olabilir mi? sorusuna yanıt bulabilmek için Hollanda ve Almanya'da 56 katılımcı ile çevrim içi bir anket yapılmıştır. Çevrim içi anketlerin sonuçlarına dayanarak, etkinlik izleme, form koruma ve sağlık işlevselliği tüketiciler tarafindan en önemli olarak algılanmıştır. Bunun nedeni, bu tür uygulamaların olumlu ve kullanıcı dostu olarak görülmesinden dolayı olumlu bir tutumun ortaya çıkması gösterilmektedir.

Buna göre, katılımcıların yaklaşık yarısı şu anda bir veya daha fazla oyunlaştırılmış sağlık uygulaması kullanırken başka bir çeyrek bu uygulamaları kısa vadede kullanmaya hazırdır. Bu nedenle oyunlaştırma tüketicilere giyilebilir cihazlar için motive edici ve cazip etkileşim kavramları sağlayabilir, böylece sağlıklı yaşam tarzlarının tanıtımında sinerjiler gerçekleştirebilir (Spil vd., 2017, s. 3624-3625). 


\subsection{Sanal Gerçeklik Teknolojileri}

Sanal gerçeklik ile sanal ortamda bireye herhangi bir durumun içinde yaşıyormuş hissi verilmektedir. Kurgu ve teknolojiyle, gerçek ve hayalin birleştirilmesi olarak nitelendirilen sanal gerçeklik (Fuchs vd., 2011, s.3), kullanıcısına alıştırmalar yapma, test etme ve çevresini değerlendirme firsatı sunmaktadır (Rizzo ve Kim, 2005, s. 119). Bu teknolojiler; uzaktan cerrahi işlemler, artırılmış gerçeklik kullanılarak yapılan cerrahi işlemler, ameliyat öncesi planlanma yapılabilme, koruyucu sağık hizmetleri, tedavi, hasta eğitimi ve tıbbi eğitim, tıp alanındaki verilerin görselleştirilmesi gibi alanlarda katkı sağlamaktadır (Moline, 1997, s. 3).

\subsection{Teletip}

Teletıp; sağlık kuruluşuna ulaşamayan bireye sağlık hizmetini sunmak için bilgi ve iletişim teknolojilerinin kullanılmasını kapsamaktadır (Roine vd., 2001, s. 765). Teletıp uygulamaları tıbbi hizmet sunumunda, sağlık hizmetlerinin eğitim ve yönetim alanında da kullanılabilir (Hersh vd., 2006, s. 3). Bu hizmetin sunumu, akıllı telefonlar, mobil cihazlar, telefonlar ve çeşitli telekomünikasyon cihazlarıyla sağlanır. Teletıp, sağlık kuruluşlarına ulaşımın zor olduğu bölgelerdeki bireylere sağlık hizmeti sunarken aynı zamanda maliyetleri azaltmakta, akut ya da kronik tüm şikâyetlere anında müdahale etmeyi kolaylaştırmaktadır (Dorsey ve Topol, 2016, s. 154).

Kovid-19 pandemisinde de yoğun bir şekilde kullanılan teletıp uygulamaları, sağık hizmeti almak için başvuran bireylerin sayısını azaltmak amacıyla elektronik hasta kayıtlarının alındığı WEB tabanlı bir uygulamadır. Hekimlerin ve hastaların akıllı telefon ya da bilgisayar kullanarak 24 saat iletişim kurmalarını sağlayan ve acil servise gelmeden önce sınıflandırma yapan bir sistem olarak bilinen teletıp, kovid-19 pandemisinde sağlık sistemindeki tüm birinci basamak hastaları için kullanılabilir hâle getirilen ve hastaları kovid-19 belirtileri olup olmamasına göre yönlendirilen bir sistemdir. Teletıp uygulaması ile hastanelerde oluşan yoğunluğun önüne geçilebilmekte ve sağıı çalışanlarının kovid-19 pandemisine yakalanma oranları azalmaktadır (Güner vd., 2021, s. 70-71).

\subsection{Mobil Sağlık (M-Sağlık) Teknolojileri}

M-Sağıı; hasta takip cihazları, akıllı cep telefonları, kişisel dijital asistan görevi gören cihazlar ve bazı diğer kablosuz cihazların, telekomünikasyon sistemleri (3G, $4 G$ ve $5 G$ ), GPS (konum belirleme), Bluetooth, sesli mesajlaşma ve kısa mesaj gibi uygulamalarla sağlık hizmeti sunan araçlardır (WHO, 2013, s. 5). Mobil sağlık uygulamaları; adım sayma, ilaç takibi, su içme hatırlatması, kalori ve nabız ölçme, fitness alıştırmaları, kronik rahatsızlıkların ve bulaşıcı hastalıkların taki- 
bini yapmak amacıyla kullanılır (Tezcan, 2016, s. 45). Söz konusu uygulamalar, bireyin sağlık durumunu kontrol altında tutmasını sağlamakta ve sağlığıyla ilgili bilgilere istediği zaman ve yerden erişim firsatı sunmaktadır. Aynı zamanda hasta, hekim ve sağlık kuruluşu arasındaki iletişimi sağlayarak istenilmeyen durumlarda müdahale edilmesini ve sağlık hâlinin devam ettirilmesini kolaylaştırır (Güler ve Eby, 2015, s. 46). M-Sağıı müdahalelerinin oyunlaşttrımasının, sigarayı bırakma sürecinde nasıl bir davranış değişikliğine yol açtığını araştıran bir çalışmada, 16 sigara içicisi ile 5 haftalık yarı yapılandırılmış 4 görüşme yapılmıştır. Oyunun kat-lımı için varlığı gerekli olan 3 kritik faktör belirlenmiştir. Bunlardan birincisi, kullanıcı tarafindan bilinen açık amaç, ikincisi kullanıcı hizalaması (oyun ve kullanıcı hedeflerinin uyumu) ve üçüncüsü (iyi tasarlanmış bir oyun) fonksiyonel faydadır. Bu çerçevede çalışma sonucunda oyunlaştırmanın, mevcut sigara bırakma programlarında bulunan davranışsal destek bileşeninin yerini alabilecek veya destekleyebilecek düşük maliyetli, etkili bir çözüm potansiyeli taşıdığı vurgulanmıştır (El-Hilly vd., 2016, s. 1).

\subsection{E-Sağlık}

E-sağlık; hasta, sağlık çalışanları ve hasta yakınları tarafindan kullanılan sağıı hizmetine erişimi, hizmet kalitesi ve verimliliği etkileyen internetle ilgili teknolojiler olarak ifade edilebilir (Broderick ve Smaltz, 2003, s. 1). E-sağlık; görüntülü arama, tıbbi hizmet sunan WEB siteleri, kısa mesaj, sağlık bilgi sistemleri, bireyin sağlık bilgilerinin bulunduğu uygulamalar ve sistemlerle sağlanmaktadır. E-sağlık hizmet sunumunda verimli, eşit, kaliteli ve etik ilkelere uygun hizmet sunulması gibi işlevleri yerine getirir. Söz konusu uygulamalar; sınırlı kaynaklar ve uzmanlık gerektiren konularda hastanın hastaneye ulaşma imkânı bulunmadığında internetten muayene işleminin gerçekleşmesini sağlar. Aynı zamanda internetten bağlantı sağlanarak, farklı doktorların görüş ve önerileri alınarak teşhis konulabilir (Broderick ve Smaltz, 2003, s. 3; Andreassen vd., 2007, s. 5). Sağlık kuruluşlarına entegre bir e-sağlık sistemi, bireylerin sağlık verilerinin tek bir sistemde toplanıp salgın ve sağlık sonuçlarının epidemiyolojik takibi, aşılama, hizmetin değerlendirilmesi, bölgelere ve illere göre analizlerin yapılması ve istatistiklerin oluşturulmasına imkân vermektedir (Asi ve Williams, 2017, s. 3). E-sağlık uygulamalarının farkındalığına yönelik bir araştırmada sağlık alanında öğrenim gören öğrencilerin sınıf düzeyleri yükseldikçe e-sağlık uygulamalarına ilişkin bilgi düzeyinin artthğı belirlenmiştir (Eke vd. 2019, s. 520). E-sağıı alanında yapılan çalışmalara ülkeler boyutunda bakıldığında, en üretken ülkenin \%22.72 oranıyla Amerika Birleşik Devletleri (ABD) olduğu görülmüştür. ABD'nin arkasından \%10.39 ile Hollanda, \%9.89 ile Almanya, \% 9.65 ile Avustralya, \% 8.98 ile İngiltere, \% 7.21 ile 
Kanada ve \% 5.34 ile İspanya gelmektedir. Diğer ülkelerin oranının \%5'in altında kaldığı görülmüştür (Koca, 2021, s. 118).

\subsection{D Yazıcılar}

İki boyutlu çıktıların alındığı yazıcıların gelişmiş versiyonları olarak tanımlanan 3D yazıcılar, otomotiv, uzay ve savunma alanlarının yanı sıra sağlık sektöründe de kullanılmaktadır. 3D yazıcılar özellikle tıbbi modellemeler ve tıbbi cihazların geliştirilmesi, implantlar ve protezlerin oluşturulmasında kullanılmaktadır (Dodziuk, 2016, s. 283).

\subsection{Hayat Eve Sığar Uygulaması}

Dünyada ve Türkiye'de kovid-19 pandemisi nedeniyle birçok mobil uygulama hayata geçirilmiştir. Pandemi ile mücadelede Çin'de teletıp ağı kurulmuş, Singapur'da TraceTogether, ABD'de CovidWatch, Endonezya'da PeduliLindungi uygulamaları hayata geçirilmiştir (Sarbadhikari ve Sarbadhikari, 2020). Türkiye'de "Hayat Eve Sığar", "Korona Önlem" ve "Filyasyon ve İzolasyon Takibi" uygulamaları Sağıı Bakanlığı tarafindan geliştirilmiştir. "Hayat Eve Sığar" mobil uygulaması, Sağıık Bakanlığınca vatandaşları kovid-19 pandemisi ile ilgili bilgilendirmek, yönlendirmek, yaşanabilecek salgın hastalık ile ilgili riskleri en az düzeye indirmek ve virüsün yayılmasını önlemek amacıyla kullanılmaktadır. Uygulama ile kullanıcılar şehirlerdeki pandemi haritalarına ulaşabilmekte, seyahat ederken ya da herhangi bir kuruma girerken bireylerin risk taşıyıp taşımadığı belirlenmektedir. Aynı zamanda en yakın eczane/hastane, risk hesaplama, ihbarda bulunma, QR kod ile güvenli alanları belirleme gibi tespitlerin yapılabildiği bir uygulamadır (SB, 2020; Kelleci vd., 2020, s. 68). "Korona Önlem" mobil uygulaması pandemi konusunda bilgi sağlamak ve yönlendirmek amacıyla geliştirilirken, "Filyasyon ve İzolasyon" takip uygulaması pozitif vakaların aile yakınları, çalışma arkadaşları, temasta bulunduğu insanların sağıı durumlarını düzenli olarak takip edebilmek amacıyla kullanılmaktadır (Kelleci vd., 2020, s. 68). Toplumun yoğun bir şekilde kullandığı akıllı telefonlar kovid-19 pandemi temaslı takibinde otomatik ve güvenilir cihazlar olarak değerlendirilmiştir (Ranisch vd., 2020). Bu bağlamda "Hayat Eve Sığar" gibi uygulamalar aracılığıyla pandemi ile mücadele daha kolay hâle gelmiştir. Dünyada pandeminin başlama tarihinden itibaren "Hayat Eve Sığar" gibi benzer özelliklere sahip 346 farklı mobil uygulama geliştirildiği bildirilmektedir (Bassi vd., 2020, s. 468). Yapay zekâ ile algoritmaların tahminleme aracı olarak kullanılarak analizlerin yapılması, $5 \mathrm{G}$ teknolojisinin kullanılarak bireylerin etkileşimde olmasının sağlanması, robotlar aracılığıyla vücut ısılarının saptanması, akıllı uygulamalarla 
takip haritalarının oluşturulması gibi çalışmalar kovid-19 ile mücadelede enformasyon teknolojilerinin Çin'de etkili bir şekilde kullanıldığını ortaya koymaktadır (Kara ve Karanfiloğlu, 2020, s. 96).

\section{Sonuç}

Eğitim, pazarlama, ekonomi, politika, tanıtım, reklam ve sağlık alanında önem kazanan oyunlaştırma; herhangi bir konuda bireyi eğitmek, bilinçlendirmek, yönlendirmek ve iyileştirmek amacıyla oyunların kullanıldığı bir ortamı ifade etmektedir. Hiç kuşkusuz bu oyunların temelinde motivasyon, hedef, ödül ve başarı bulunmaktadır. Bu bağlamda oyunlar iyi bir motivasyon kaynağı olarak değerlendirilebilir. Oyunun iyi bir motivasyon aracı olarak görülmesi, aynı zamanda hedeflere ulaşmada itici bir güç olması ve ödülü kazanmada önemli bir unsur olması oyunlaştırmayı önemli hâle getirmektedir. Özellikle sağlık alanına uyarlanan oyunların hem sağlık çalışanlarının işlerini kolaylaştırması hem de sağlık okuryazarlığı seviyesini yükseltme anlamında katkı sağladığı bilinmektedir. Oyunlaştırma yöntemi ile örneğin sigara bırakma, obezite ile mücadele etme, düzenli egzersiz yapma, dengeli beslenme planı hazırlama, bağımlılıklar ile mücadele etme, hijyen kurallarına uyma ve temiz olma, diş firçalama gibi konular keyifli hâle getirilmektedir. Oyunlaştırma uygulamalarının hastanenin rotasını belirleme, çeşitli sağlık uygulamaları aracılığıyla egzersiz oluşturma, ilaç kullanımı saatini ayarlama, kalp mesajı yapabilme, dengeli beslenme gibi bilinçli ve sağlıklı olma yolunda kolaylaştırıcı bir araç olarak kabul edilmektedir. Bu bağlamda oyunlaştırmanın sağlık okuryazarlığını keyifli hâle getirici ve hatırlatıcı bir araç olduğu değerlendirilebilir. Alanyazında yapılan araştırmalar doğrultusunda sağlık alanında oyunlaştırmanın bazı olumsuz yönleri bulunsa da genel olarak sağlık alanına olumlu yönde katkı sağladığı ortaya çıkmaktadır. Genç neslin dijital teknolojiyi başarılı bir şekilde kullandığı göz önüne alındığında oyunlaştırmanın sağlık alanında etkisinin ileriki yıllarda daha da artacağı söylenebilir. Ayrıca dijital sağlık uygulamalarının hızlı ve çabuk erişilebilir olması, cepte taşınabilmesi sağlık okuryazarlığını geliştirmesi açısından önemli bir potansiyel olarak görülebilir. Bu bağlamda sağlık alanında oyunlaştırma, bireylerin sağıık davranışlarında olumlu yönde bir kalıcı değişikliği desteklemek ve sürdürmek adına önemli bir araç olarak kabul edilebilir. Alanyazında yapılan araştırmalar da oyunlaştırmanın fiziksel aktivite gibi sağlıkla ilgili çok çeşitli etki ölçümlerini olumlu etkileme potansiyeline sahip olduğunu gösteren umut verici sonuçlar ortaya koymuştur. Yapılan araştirmalar bağlamında sağlık alanında oyunlaştırmanın sağlık okuryazarlığının temelini oluşturan anlayabilme ve kavrayabilme yeterliliğini geliştireceğini söylemek mümkündür. 


\section{Çıkar Çatışması Beyanı}

Makale yazarları herhangi bir çıkar çatışması olmadığını beyan etmiştir.

\section{Kaynakça}

Ajami, S., \& Bagheri-Tadi, T. (2013). Barriers for Adopting Electronic Health Records (EHRs) by Physicians. ActaInformatica Medica, 21(2): 129-134.

Andreassen, H. K.,Bujnowska-Fedak, M. M., Chronaki, C. E., Dumitru, R. C., Pudule, I., Santana, S., Voss, H., \&Wynn, R. (2007). European Citizens' Use of E-health Services: A Study of Seven Countries. BMC Public Health, 7(1): 53.

Asi, Y. M.,\& Williams, C. (2017). The Role of Digital Health in Making Progress toward Sustainable Development Goal (SDG) 3 in Conflict-affected Populations. International Journal of Medicalin Formatics, (114): 114-120.

Bamidis, P.D.,Gabarron, E., Hors-Fraile, S., Konstantinidis, E., Konstandinidis, S., \&Rivera, O. (2016). Gamification and Behavioral Change: Techniques for Health Social Media, Participatory Health Through Social Media (Ed. Shabbir Syed-Abdul, Elia Gabarron and Annie Y.S. Lau), Chapter 7, pp. 112-135. Academic Press.

Bassi, A., Arfin, S., John, O., \& Jha, V. (2020). An Overview Of Mobile Applications (Apps) To Support The Coronavirus Disease 2019 Response In India. Indian Journal of Medical Research, 151 (5): 468-473.

Blumenthal, D. (2017). Data Withholding in the Age of Digital Health. The Milbank Quarterly, 95(1): 15-18.

Bonato, P. (2010). Advances in Wearable Technology and its Medical Applications. Paper Presented at the Engineering in Medicine and Biology Society (EMBC), 2021-4.

Bottorff, J. L.,Struik, L. L., Bissell, L. J. L., Graham, R., Stevens, J. \&Richardson, C. G. (2014). A Social Media Approach to Inform Youth About Breast Cancer and Smoking: An Exploratory Descriptive Study. Collegian, 21 (2): 159-168.

Broderick, M., \& Smaltz, D. H. (2003). E-Health Defined. Symposium Conducted the Meeting of the Proceedings of Student Research Day, CSIS, Pace University, May 9th, New York, NY.

Buckley, P., \& Doyle, E. (2016). Gamification and Student Motivation. Interactive Learning Environments, 24(6):1162-1175. 
Chen, C.H., Liu, G.Z., \& Hwang, G.J. (2016). Interaction Between Gaming and Multistage Guiding Strategies on Students Field Trip Mobile Learning Performance and Motivation. British Journal of Educational Technology, 47(6): 1032-1050.

Cimasi, R.J., Sharamitaro, A.P., \&Seiler, R.A. (2013). The Association between Health Literacy and Preventable Hospitalizations in Missouri: Implications in an Era of Reform. Journal of Health Care Finance, 40(2): 1-16.

Dodziuk, H. (2016). Applications of 3D Printing in Healthcare. Kardiochirurgia i Torakochirurgia Polska Polish Journal of Thoracic and Cardiovascular Surgery, 13(3): 283-293.

Domínguez, A.,Saenz-de-Navarrete, J., de-Marcos, L., Fernández-Sanz, L., Pagés, C., \& Martínez-Herráiz, J.J. (2013). Gamifying Learning Experiences: Practical Implications and Outcomes. Computers\& Education, 63 (1): 380-392.

Dorsey, E. R. \& Topol, E. J. (2016). State of Telehealth. New England Journal of Medicine, 375(2): 154-161.

Eichler, K.,Wieser, S., \& Brügger, U. (2009). The Costs of Limited Health Literacy: A Systematic Review. International Journal of Public Health, (549): 313-324.

Eke, E., Kişi, M. \& Uğurluoğlu, D. (2019). E-sağlık Uygulamalarının Farkındalığına Yönelik Bir Araştırma. Mehmet Akif Ersoy Üniversitesi Iktisadi ve İdari Bilimler Fakültesi Dergisi, 6(2): 510-522.

El-Hilly, A.A.,Iqbal, S.S., Ahmed, M., Sherwani, Y., Muntasir, M., Siddiqui, S., Al-Fagih, Z., Usmani, O., \& Eisingerich, A.B. (2016). Game On? Smoking Cessation Through the Gamification of mHealth: A Longitudinal Qualitative Study. JMIR Serious Games, 4(2): 1-13.

Ezezika, O., Oh, J., Edeagu, N., \& Boyo, W. (2018). Gamification of Nutrition: A Preliminary Study on the Impact of Gamification on Nutrition Knowledge, Attitude and Behaviour of Adolescents in Nigeria. Nutrition and Health, 24(3): 137-144.

Freedman, D.A., Bess, K.D., Tucker, H.A., Boyd, D.L., Tuchman, A.M., \& Wallston, K.A. (2009). Public Health Literacy Defined. American Journal of Preventive Medicine, 36(5): 446-451.

Fuchs, P., Moreau, G., \& Guitton, P. (2011). Virtual Reality: Concepts and Technologies (1 st ed.). Leiden: CRC Press, Inc.

Gallan, A., Jarvis, C., Brown, S. \& Bitner, M.(2013). Customer Positivity and Participationin Services: An Empirical Test in a Health Care Context. Journal of the Academy of Marketing Science, 41(3): 338-356. 
Güler, E., \& Eby, G. (2015). Akıllı Ekranlarda Mobil Sağlık Uygulamaları. Eğitim ve Öğretim Araştırmaları Dergisi, 4(3): 45-51.

Güner, Y., Güner, K.E., \& Çilingir, D. (2021). Yeni Tıp Koronavirüs ve Sağlık Sistemindeki Teknolojik Yenilikler. Bezmialem Science, 9 (1): 69-73.

Hamari, J., \& Koivisto, J. (2015). Why do People Use Gamification Services?, International Journal of Information Management, 35(4): 419-431.

Haruna, H., Hu, X., Chu, S.K.W., Mellecker, R.R., Gabriel, G., \& Ndekao, P.S. (2018). Improving Sexual Health Education Programs for Adolescent Students trough Game-Based Learning and Gamification. International Journal of Environmental Research and Public Health, 15 (9): 1-26.

Hart, C. (2001). Doing a Literature Search: A Comprehensive Guide for the Social Sciences. London: Sage.

Herselman, M. Botha, A., Toivanen, H., Myllyoja, J., Fogwill, T., \& Alberts, R. (2016). A Digital Health Innovation Ecosystem for South Africa (pp.394-404). IST-Africa 2016 Conference Proceedings, 9-11 May 2016, Durban, South Africa.

Hersh, W. R., Hickam, D. H., Severance, S. M., Dana, T. L., Krages, K. P., \& Helfand, M. (2006). Diagnosis, Access and Outcomes: Update of a Systematic Review of Telemedicine Services. Journal of Telemedicine and Telecare, 12 (2): 3-31.

Hudes, M. K. (2017). Fostering Innovation in Digital Health a New Ecosystem. Paper Presented at the Microelectronics Symposium (Pan Pacific), 1-6.

Järvinen, A. (2008).Games Without Frontiers: Theories and Methods for Game Studies and Design (Published PhD Thesis). Tampere University Press, Finlandiya.

Joy, M.M.\& Chiramel, M.J. (2017). Fun is the Future: A Collection of Compelling Gamification Success Stories. Educreation Publishing, https:// play.google.com/ books/ reader?id=UU0oDwAAQBAJ\&hl=tr\&pg=GBS.PR4.

Juárez, G. H., \& Carballo, M. M. (2016). Learning Gains, Motivation and Learning Styles in a Gamified Class. The International Journal of Engineering Education, 32(1): 438-447.

Juul, J. (2003). The Game, the Player, the World: Looking for a Heart of Gameness. In Level Up: Digital Games Research Conference Proceedings. Edited by Marinka Copier and Joost Raessens, Utrecht: Utrecht University, Hollanda.

Kanj, M. \& Mitic, W. (2009). Health Literacy and Health Behaviour. World Health Organization. http://www.who. int / healthpromotion/conferences/7gchp / 
Track1_Inner. pdf. (02.04.2020).

Kapp, K. M. (2012). The Gamification Of Learning and Instruction: Game-based Methods and Strategies for Training and Education. San Francisco, CA: John Wiley ve Sons.

Kara, N., \& Karanfiloğlu, M. (2020). İletişimin Dijitalleşmesi: Pandemi (COiD-19) ve Enformasyon Teknolojileri. AJIT-e: Bilişim Teknolojileri Online Dergi, 11(42): 88-99.

Karahan, Z.C., Aytuğ Koşan, M.A., \& Demirören, M. (2014). The Effect of Gaming Approach on Learning in Basic Microbiology Education: A Pilot Study. Marmara Medical Journal, 27 (3): 184-189.

Kelleci, M., Tel, H., \& Kısaoğlu, Ö. (2020). COViD-19 Pandemisi ile Kullanıma Giren Akıllı Telefon Uygulamaları, ss. 66-70. 4. Uluslararası Hemşirelik ve İnovasyon Kongresi, 19-20 Aralık 2020, İstanbul.

King, D., Greaves, F., Exeter, C., \& Darzi, A. (2013). Gamification: Influencing Health Behaviours With Games. Journal of the Royal Society of Medicine, (106): 76-78.

Koca, G. (2021). E-Sağlık ve İlgili Kavramların Google Trend Analizi. Sosyal Bilimlerde E-Uzantılı Kavramlar içinde (ss. 115-131) Ed. C. Hatipoğlu, i̇stanbul: Efe Akademi Yayınevi.

Kostenius, C., Hallberg, J., \& Lindqvist, A.K. (2018). Gamification of Health Education: Schoolchildren's Participation in the Development of a Serious Game to Promote Health and Learning, Health Education, 118(4): 354-368.

Leclercq, T., Hammedi, W., \& Poncin, I. (2018). The Boundaries of Gamification for Engaging Customers: Effects of Losing a Contest in Online Co-creation Communities.Journal of Interactive Marketing, (44): 82-101.

Lupton, D. (2013). The Digitally Engaged Patient: Self-Monitoring and Self-Care in the Digital Health Era. Social Theory and Health, 11(3): 256-270.

Mackert, M., Mabry-Flynn, A., Champlin, S., Donovan, E. E., \& Pounders, K. (2016). Health Literacy and Health Information Technology Adoption: The Potential for a New Digital Divide. Journal of Medical Internet Research, 18(10): 1-16.

MacLeod, S., Musich, S., Gulyas, S., Cheng, Y., Tkatch, R., Cempellin, D., Bhattarai, GR., Hawkins, K., \& Yeh, C.S. (2017). The Impact of Inadequate Health Literacy on Patient Satisfaction, Healthcare Utilization, and Expenditures Among older Adults. GeriatricNursing,38 (4): 334-341.

Moline, J. (1997). Virtual Reality for Health Care: A Survey. In: Studies in Health. Technology and Informatics, 3-34. 
Nutbeam, D. (2000). Health Literacy as a Public Health Goal: A Challenge for Contemporary Health Education and Communication Strategies into the 21st Century. Health Promotion International, 15 (3): 259-267.

Ölmez, E.H. \& Barkan, O.B. (2015). Sağlık Okuryazarlık Düzeylerinin Belirlenmesi ve Hasta Hekim İlişkisinin Değerlendirilmesi. Balkan Sosyal Bilimler Dergisi, 4(8): 121-127.

Parker, R. M., Williams, M. V., Weiss, B. D., Baker, D. W., Davis, T. C., Doak, C. C., \& Schwartzberg, J. G. (1999). Health Literacy-report of the Council on Scientific Affairs. Jama-Journal of the American Medical Association, 281 (6): 552-557.

Pesare, E.,Roselli, T., Corriero, N., \& Rossano, V. (2016). Game-based Learning and Gamification to Promote Engagement and Motivation in Medical Learning Contexts. Smart Learning Environments, 3(5): 1-21.

Prensky, M. (2007). Dijital Game-based Learning. St. Paul, MN: Paragon House.

Radovick, S., Hershkovitz, E., Kalisvaart, A., Koning, M., Paridaens, K., \& Kamel Boulos, M.N. (2018). Gamification Concepts to Promote and Maintain Therapy Adherence in Children with Growth Hormone Deficiency. Multidisciplinary Scientific Journal, (1): 71-80.

Rajani, N.B., Weth, D., Mastellos, N., \& Filippidis, F.T.(2019). Use of Gamification Strategies and Tactics in Mobile Applications for Smoking Cessation: A Review of the UK Mobile App Market. BMJ, 9(6): 1-7.

Ranisch, R., Nijsingh N., Ballantyne A., Buyx A., Friedrich O., Hendl T., Hurst S., Marckmann G., Munthe C., \& Wild V., (2020). Ethics Of Digital Contact Tracing Apps For The Covid-19 Pandemic Response. Kompetenznetz Public Health COVID-19, 1-17.

Rizzo, A. S. \& Kim, G. J. (2005). A SWOT Analysis of the Field of Virtual Reality Rehabilitation and Therapy. Presence: Teleoperators\& Virtual Environments, 14(2): 119-146.

Roine, R.,Ohinmaa, A., \& Hailey, D. (2001). Assessing Telemedicine: A Systematic Review of the Literature. Canadian Medical Association Journal, 165(6): 765-771.

Rudd, R.,Kirsch, I., \& Yamamoto, K. (2004). Literacy and Health in America. Policy Information Report. Educational Testing Service.

Sarbadhikari, S., \& Sarbadhikari, S.N. (2020). The Global Experience of Digital Health Interventions in COVID-19 Management. Indian Journal of Public Health, (64):117-124. 
Sağıık Bakanlığı (SB). (2020). Hayat Eve Sığar Mobil Uygulaması. https://hayatevesigar. saglik.gov.tr/. (Erişim Tarihi: 24.12.2021).

Sağlık Sektörü ve Oyunlaştırma Trendleri (2012). https://sosyalmedya.co/sagliksektoru-ve-oyunlastirma/ (Erişim Tarihi: 24.12.2021).

Schmidt-Kraepelin, M., Thiebes, S., Stepanovic, S., Mettler, T., \& Sunyaev, A. (2019). Gamification in Health Behavior Change Support Systems-A Synthesis of Unintended Side Effects. 14th International Conference on Wirtschaftsinformatik, February 24-27, 2019, Siegen, Germany.

Sorensen K, Van den Broucke S, Fullam J, Doyle G, Pelikan J, Slonska Z., \& Brand, H. (HLS-EU) Consortium Health Literacy Project European. (2012). Health Literacy and Public Health: A Systematic Review and Integration of Definitions and Models. BMC Public Health,(12): 80.

Spil, T., Sunyaev, A., Thiebes, S., \&Van Baalen, R. (2017). The Adoption of Wearables for a Healthy Lifestyle: Can Gamification Help?. Proceedings of the 50th Hawaii International Conference on System Sciences, 3617-3626.

Steinert, A., Buchem, I., Merceron, A., Kreutel, J., \& Haesner, M. (2018). A WearableEnhanced Fitness Program for Older Adults, Combining Fitness Trackers and Gamification Elements: The Pilot Study Fmooc@Home, Sport Sciences for Health, 14 (8): 275-282.

Şahinöz, T., Şahinöz, S., \& Kıvanç, A. (2018). Üniversite Son Sınıf Öğrencilerinin Sağlık Okuryazarlığı Düzeyleri Üzerine Karşılaştırmalı Bir Araştırma. Gümüşhane Üniversitesi Sağlık Bilimleri Dergisi, 7(3): 71-79.

Tehrani, K., \& Michael, A. (2014). Wearable Technology and Wearable Devices: Everything YouNeed toKnow.http://www.wearabledevices.com/what-is-a-wearabledevice/ (Erişim Tarihi: 01.04.2020).

Tezcan, C. (2016). Sağlığa Yenilikçi Bir Bakış Açısı: Mobil Sağlık. In: İstanbul: TÜsiAD-T.

Tüfekçi, H. (2016). Sağlık Hizmetlerinde Oyunlaştırma Tasarımı ve Değerlendirmesi, Bahçeşehir Üniversitesi Fen Bilimleri Enstitüsü Bilgi Teknolojileri. Yüksek Lisans Tezi, İstanbul.

Wagner, C.V., Knight, K., Steptoe, A., \& Wardle, J.(2007). Functional Health Literacy and Health-Promoting Behaviour in a National Sample of British Adults. Journal of Epidemiol Community Health, (61): 1086-1090.

Wen, M.H. (2017). Applying Gamification and Social Network Techniques to Promote Health Activities, Proceedings of the 2017 IEEE International Conference on 
Applied System Innovation IEEE-ICASI 2017-Meen, Prior \& Lam (Eds), 531-534.

Wolf, C., Bott, S., \& Hernandez, I. (2018). Teaching About the Health Care Industry Through Gamification. American Journal of Pharmaceutical Education, 82 (4): 305-307.

World Health Organization (2013). Health Literacy the Solid Facts. Regional Office for Europe Copenhagen; Denmark.

Yakar, B., Gömleksiz, M., \& Pirinççi, E. (2019). Bir Üniversite Hastanesi Polikliniğine Başvuran Hastaların Sağıık Okuryazarlığı Düzeyleri ve Etkileyen Faktörler. Euras Journal of Family Medicine (EJFM), 8(1): 27-35.

Yılmazel, G. \& Çetinkaya, F. (2016). Sağlık Okuryazarlığının Toplum Sağlığı Açısından Önemi. TAF Preventive Medicine Bulletin, 15(1): 69-74.

Zichermann, G. \& Cunningham, C. (2011). Gamification by Design: Implementing Game Mechanics in Web and Mobile Apps. O'Reilly Media, Inc.

Zülam, T. (2019). Kanser Hastalarına Yönelik Oyunlaştırımış Bir Web Ortamın Tasarımı ve Geliştirilmesi. Yüksek Lisans Tezi. Afyon Kocatepe Üniversitesi Fen Bilimleri Enstitüsü, Afyon.

Zimmerling, E., Höllig, C. E., Sandner, P. G., \& Welpe, I. M. (2019). Exploring the Influence of Common Game Elements on Ideation Output and Motivation. Journal of Business Research, (94): 302-312. 
